\title{
Revitalisasi Kawasan Braga Dengan Konsep Pedestrian MaLL Sebagai Wujud Kawasan Pusaka Kota Bandung
}

\author{
Angga Nugraha, Ahmad Farkhan, Kusumaningdyah N.H. \\ Program Studi Arsitektur \\ Jurusan Arsitektur Fakultas Teknik \\ Universitas Sebelas Maret Surakarta \\ E-mail : arsitek@uns.ac.id
}

\begin{abstract}
Braga District became the only one that showed a luxurious lifestyle at 1920-1945, especially the elite European people who live in the Hindia Belanda territory. After that period, Braga District has decreased quality and quantity, such as illegal parking, abandoned buildings, etc. Braga District is need a revitaliation efforts to became economy district and market place for tourists and try to restore the image of Braga District as lifestyle district in Bandung City. Braga and Bandung City has potencial as a creative economic development in Bandung City will create new economic activities in Braga District. Braga District revitalization efforts must begin with a variety of problem-solving methods. First, case studies is to find out the problems that arise in the Braga District. Second, field studies is to collect data existing in Braga District. Third, literature studies is to collect a theories relating to the revitalization of Braga District. After the analysis that produce adesign concept. Pedestrian mall concept will be applied to add value to pedestrians and the other activities user to be more comfortable doing activities in the Braga District. Development of the area in the form of an underground mall aiming to increase the economy and community areas in the Braga District who can be filled by the user of creative economic especially in the fashion things. Design of Braga District refers to the 1920-1945 periode that based on the design of the European Architectural style or Art Deco Architectural style that was popular at that time. Old building conservation efforts in Braga district, new facilities and underground mall in design refers to the style of Art deco architecture. As well as the revitalization of the Braga District goal to become a pilot project area of Bandung City heritage, so the protection and preservation of cultural assets can be monitored by all people.
\end{abstract}

Keywords: Braga District, Pedestrian Mall, Revitalization

\section{PENDAHULUAN}

"Pusaka yang diterima dari generasigenerasi sebelumnya sangat penting sebagai landasan dan modal awal bagi pembangunan masyarakat Indonesia di masa depan, karena itu harus dilestarikan untuk diteruskan kepada generasi berikutnya dalam keadaan baik, tidak berkurang nilainya, bahkan perlu ditingkatkan untuk membentuk pusaka masa datang" (Piagam Pelestarian pusaka Indonesia, 2003).

Braga merupakan kawasan terkenal sejak masa kejayaan Braga pada periode 1920-1945. Kawasan Braga menjadi tempat satu-satunya yang menunjukan lifestyle yang mewah kepada kalangan elit saat itu khususnya orang-orang Eropa yang tinggal di Hindia Belanda.

Seiring berjalannya waktu, Braga mengalami penurunan kualitas dan kuantitas kawasan, seperti parkir liar, bangunan terbengkalai, pembangunan gedung baru yang semerawut dan menjamurnya pusat perbelanjaan baru di Kota Bandung.Tampilan Kawasan Braga menjadi kurang menarik untuk dikunjungi wisatawan.

Upaya mengembalikan citra Kawasan Braga seperti pada masa kejayaannya, perlu adanya upaya revitalisasi Kawasan Braga agar menjadi kawasan perekonomian dan perdagangan yang ramai oleh wisatawan. Potensi-potensi yang ada di Braga dan Kota Bandung seperti perkembangan ekonomi kreatif di Kota Bandung akan membuat kegiatan perekoniomian baru di Braga dan fungsi kebaharuan Kawasan Braga akan sangat beragam, namun harus disesuaikan dengan nilai sejarah Braga pada periode 1920-1945an.

Rangkaian upaya menghidupkan kembali kawasan yanga mengalami penurunan kualitas fisik dan non fisik, meningkatkan nilainilai vitalitas yang strategis dan signifikan dari 
kawasan yang mempunyai potensi dan/atau mengendalikan kawasan yang cenderung tidak teratur, untuk mengembalikan atau menghidupkan kembali kawasan dalam ikatan kota sehingga berdampak pada kualitas hidup warganya, melalui peningkatan kualitas lingkungan kawasan (Permen PU No. 18/PRT/M/2011). Menghidupkan Kawasan Braga dapat dengan cara penataan fisik, baik terhadap bangunan-bangunan tua peninggalan pemerintahan Hindia Belanda maupun infrastrukturnya, seperti pedestrian, street furniture, lalu lintas dan fasilitas-fasilitas penunjang lainnya. Serta penataan non fisik dari pengembangan ekonomi kreatif di Kawasan Braga.

Konsep pedestrian mall diterapkan untuk memberikan nilai tambah kepada pejalan kaki dan pelaku kegiatan lainnya agar lebih nyaman berkegiatan di Kawasan Braga. Konsep pedestrian mall ini membuat lingkungan jalur pejalan kaki dapat dipergunakan untuk berbagai kegiatan, seperti berjalan-jalan, tempat berkumpul atau berkomunikasi, beristirahat dan untuk melakukan kegiatan berbelanja. (Mulyati dkk. 2009)

Pembangunan Kawasan Braga pada periode 1920-1945an yang di atur oleh pemerintahan saat itu, mengharuskan pembangunan bangunan menggunakan desain gaya yang sedang populer pada saat itu adalah langgam Arsitektur Art deco. Begitu pula upaya revitalisasi Kawasan Braga akan berdasarkan nilai sejarah yang telah disebutkan yaitu menerapkan langgam Arsitektur Art deco sebagai tampilan Kawasan Braga.

Serta tujuan revitalisasi Kawasan Braga agat menjadi proyek percontohan kawasan pusaka Kota Bandung, agar perlindungan dan pelestarian aset-aset budaya dapat dipantau oleh semua kalangan.

\section{METODE}

\subsection{Studi Kasus}

Metode ini merupakan pengumpulan permasalahan-permasalahan yang ada di Kawasan Braga melalui berbagai macam sumber, seperti buku, koran, majalah, internet dan melakukan wawancara terhadap pihak-pihak terkait. Setelah itu, merumuskan permasalahan - permasalahan agar didapatkan solusi permasalahan yang sesuai.

\subsection{Studi Lapangan}

Metode ini merupakan pengumpulan data - data eksisting Kawasan Braga, sehingga didapat data yang akurat berdasarkan permasalahan yang ada.

\subsection{Studi Literatur}

Metode ini merupakan pengumpulan teori-teori atau peraturan-peraturan terkait untuk mencari solusi terbaik dalam perancangan dan perencanaan revitalisasi Kawasan Braga. Teori dan peraturan yang di pelajari adalah sebagai berikut;

1. Revitalisasi kawasan,

2. Ruang publik kota,

3. Langgam Arsitektur Art deco,

4. Ekonomi kreatif,

5. Kota pusaka.

\subsection{Analisis}

Analisis dilakukan untuk mendapatkan sebuah konsep perencanaan dan perancangan yang tepat untuk upaya revitalisasi Kawasan Braga. Tahap-tahap dalam melakukan analisis, sebagai berikut;

1. Mempelajari periodesasi perkembangan Kawasan Braga,

2. Menentukan konsep makro perencanaan dan perancangan,

3. Menentukan konsep mezzo,

4. Menentukan konsep - konsep mikro, seperti analisis kegiatan, tampilan kawasan, struktur dan lain-lain.

\subsection{Konsep Perencanaan dan Perancangan}

Konsep ini yang akan diterjemahkan dalam bentuk gambar desain dari perencanaan dan perancangan revitalisasi Kawasan Braga.

\section{ANALISIS}

\subsection{Analisis Periodesasi Kawasan Braga}

Analisis ini bertujuan untuk mendapatkan dasar perencanaan dan perancangan revitalisasi Kawasan Braga. Periodesasi Kawasan Braga dapat dilihat pada Tabel 1.

Tabel 1. Periodesasi Kawasan Braga

\begin{tabular}{|l|l|l|}
\hline & $1920-1945$ & Sekarang \\
\hline Kawasan & Berkembang & Kawasan \\
& Kawasan & $\begin{array}{l}\text { Wisata } \\
\text { Heritage }\end{array}$ \\
\hline
\end{tabular}




\begin{tabular}{|l|l|l|}
\hline & $\begin{array}{l}\text { Ekslusif warga } \\
\text { Belanda }\end{array}$ & $\begin{array}{l}\text { Braga, } \\
\text { Pembangunan } \\
\text { bangunan baru } \\
\text { cenderung } \\
\text { meninggalkan } \\
\text { ciri khas Art } \\
\text { deco }\end{array}$ \\
\hline $\begin{array}{l}\text { Bangunan } \\
\text { (langgam) }\end{array}$ & $\begin{array}{l}\text { Art deco dan } \\
\text { Campuran } \\
\text { Langgam Eropa } \\
\text { lainnya }\end{array}$ & $\begin{array}{l}\text { Art deco dan } \\
\text { Campuran } \\
\text { Bangunan } \\
\text { Modern }\end{array}$ \\
\hline Fungsi & $\begin{array}{l}\text { Pusat politik, } \\
\text { intelektual, seni, } \\
\text { budaya, hiburan, } \\
\text { pusat } \\
\text { perbelanjaan } \\
\text { dan jalur } \\
\text { transportasi }\end{array}$ & $\begin{array}{l}\text { Tempat } \\
\text { perbelanjaan, } \\
\text { hiburan, } \\
\text { lifestyle, seni, } \\
\text { pedagang kaki } \\
\text { lima dan } \\
\text { transportasi }\end{array}$ \\
\hline Peraturan & $\begin{array}{l}\text { Walikota } \\
\text { Bandung saat itu } \\
\text { B. Coops } \\
\text { menginginkan } \\
\text { Braga menjadi } \\
\text { pusat pertokoan } \\
\text { ekslusif bergaya } \\
\text { barat di Hindia } \\
\text { Belanda }\end{array}$ & $\begin{array}{l}\text { Kawasan } \\
\text { Heritage, } \\
\text { perbelanjaan } \\
\text { dan jasa }\end{array}$ \\
\hline
\end{tabular}

\subsection{Analisis Konsep Makro}

Upaya revitalisasi Kawasan Braga berdasarkan kepada masa kejayaannya pada periode 1920-1945, sehingga direncanakan beberapa konsep makro yang dapat mendukung perencanaan revitalisasi Kawasan Braga, yaitu :

1. Kawasan Pusaka Kota Bandung

$$
\text { Revitalisasi Braga yang }
$$

direncanakan diharapkan dapat
mengawali program kota pusaka di Bandung. Ditunjang dengan Kawasan Braga yang tumbuh dan berkembang di pusat Kota Bandung, kental akan sejarah dari pemerintahan Hindia Belanda, pengaruh pembangun bangunan langgam Art deco yang kuat.

Untuk mendukung hal tersebut, rencana tata ruang harus membuka peluang terjadinya inovasi pada tataran mikro terhadap berbagai langkah preservasi, konservasi dan berkembang dan dikelola secara efektif.

2. Kawasan Pusat Bisnis
Fungsi kebaharuan yang direncanakan agar Braga tetap berkembang menjadi pusat perekonomian yang berdasarkan sejarah Braga, yaitu memanfaatkan ekonomi kreatif yang sedang berkembang di Kota Bandung, seperti fesyen, seni rupa, musik, kuliner dan lain-lain.

Penataan fisik kawasan yang berdasar kepada kebutuhan kegiatan Braga seperti, berbelanja, berjalanjalan, berkomunitas, beristirahat dan lain-lain. Diwadahi dengan konsep pedestrian mall, yaitu konsep yang mengutamakan kenyamanan dan aksesibilitas pejalan kaki di pedestrian.

Penambahan wadah kegiatan ekonomi dan berkomunitas dengan memanfaatkan ruang-ruang yang ada di Kawasan Braga.

3. Analisis Kebutuhan Ruang Kebutuhan ruang di analisis berdasarkan pelaku kegiatan yang sudah dianalisis di antaranya, pengunjung, pengelola, petugas dan pelaku ekonomi kreatif. Analisis kebutuhan ruang dapat dilihat pada Tabel 2.

Tabel 2. Kebutuhan Ruang

\begin{tabular}{|l|l|l|}
\hline No. & Kegiatan & \multicolumn{1}{|c|}{ Jenis Ruang } \\
\hline 1 & \multirow{2}{*}{ Transportasi } & Area Parkir \\
\cline { 3 - 3 } & & Halte \\
\hline 2 & Umum & Pedestrian \\
\hline 3 & \multirow{2}{*}{ Khusus } & Perpustakaan \\
& & Retail \\
& & ATM \\
& & Foodcourt \\
\cline { 3 - 3 } & & Kantor Pengelola \\
& & Kantor Kreatif \\
\cline { 3 - 3 } & & Toilet \\
\hline
\end{tabular}

\subsection{Analisis Zonasi Kawasan}

Analisis zonasi Kawasan Braga dibagi berdasarkan area perekonomian di Kawasan Braga. Terdapat 3 area yang dapat kelompokan, seperti pada Gambar 1. 


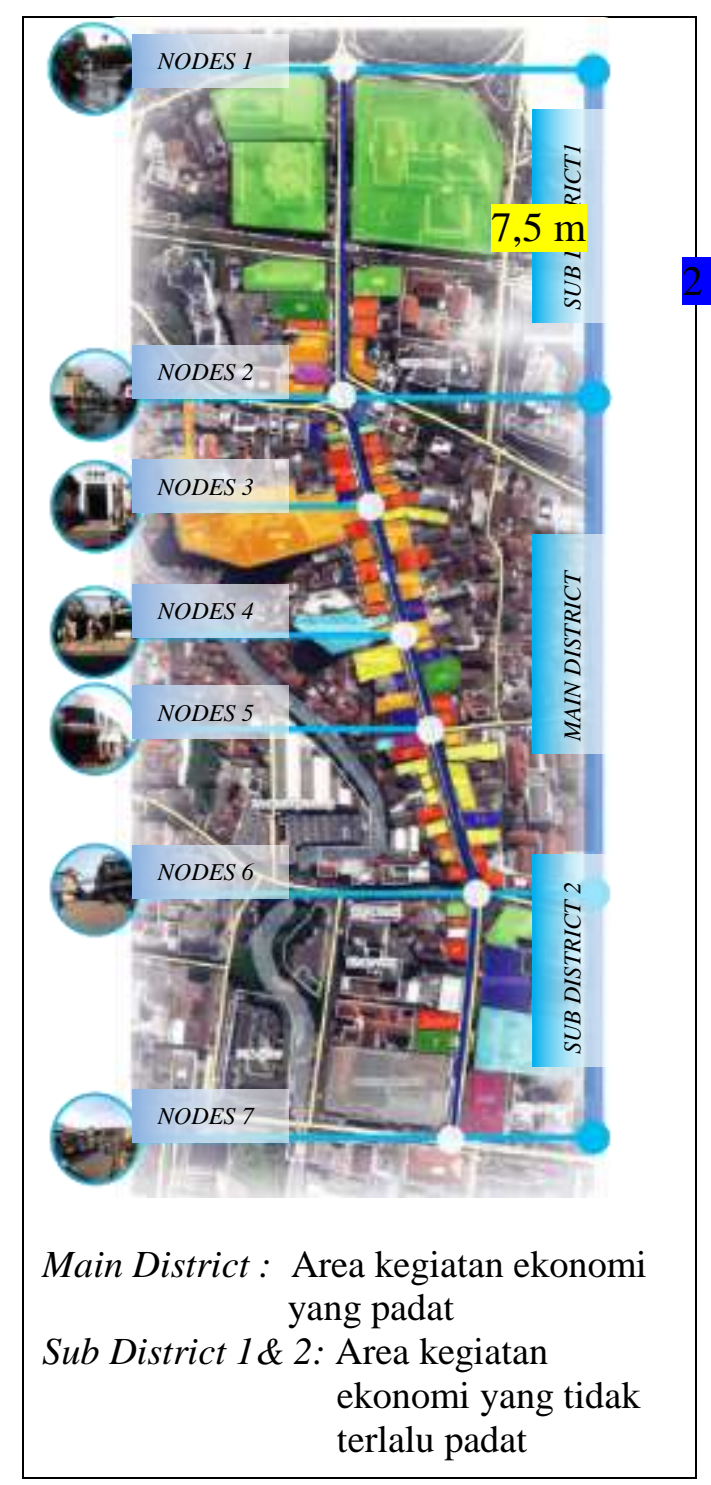

Gambar 1. Zonasi Kawasan

\subsection{Analisis Pedestrian Mall}

Analisis ini mengutamakan pejalan kaki sebagai pelaku utama kawasan, maka perlu menyiasati kendaraan bermotor yang sudah menjadi salah satu jalan penghubung di pusat Kota Bandung.

Pada Gambar 2 dapat dilihat eksisting pedestrian dengan lebar sekitar 2 meter dan jalan dengan lebar sekitar 7,5 meter yang ada di Kawasan Braga.

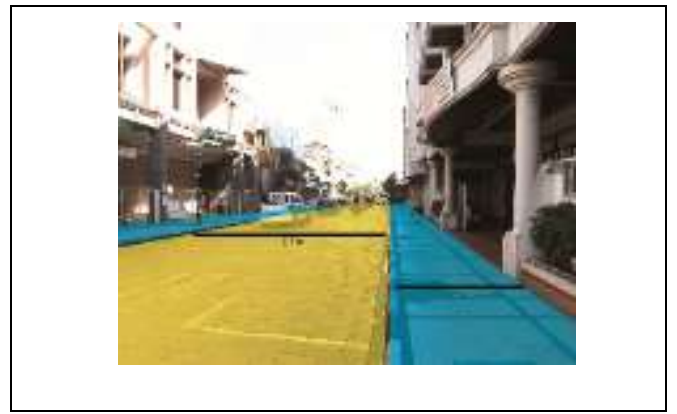

Gambar 2. Eksisting Pedestrian dan Jalan di Kawasan Braga

Pada Gambar 3 lebar pedestrian di perlebar menjadi sekitar 2,1 meter yang dapat dilalui oleh 2 pengguna berjajar dan beberapa streetfurniture. Lebar jalan berkurang menjadi sekitar 5,5 meter dapat dilalui 2 lajur kendaraan.

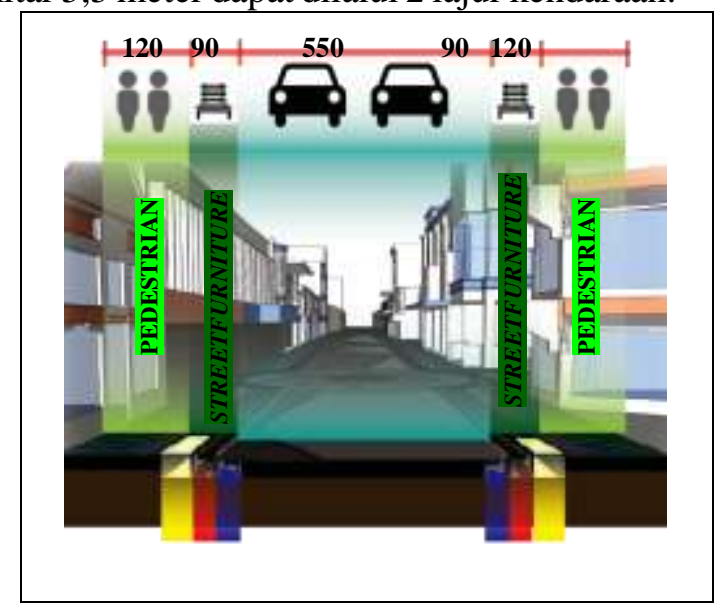

Gambar 3. Sketsa Desain Pelebaran Pedestrian

\subsubsection{Pola Pedestrian}

Pola lantai mengacu pada polapola langgam Art deco, untuk menguatkan tampilan Kawasan Braga, seperti pada Gambar 4.

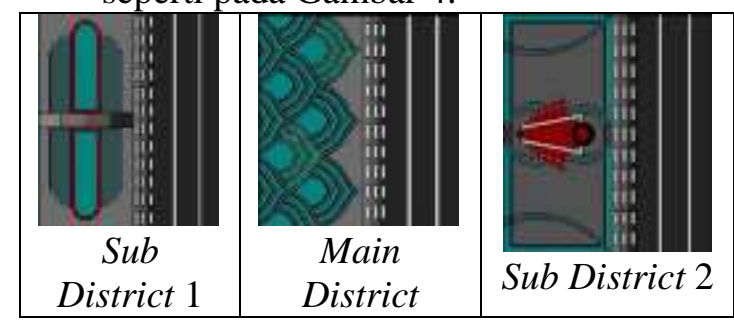

Gambar 4. Aplikasi Pola Pedestrian

\subsubsection{Pola Jalan}

Pola jalan dibuat pola penghubung antara bangunan-bangunan yang dilindungi di Braga, hal ini diterapkan untuk memberikan informasi 
kepada pengunjung terhadap bangunanbangunan yang perlu dilestarikan. Dapat dilihat pada Gambar 5.

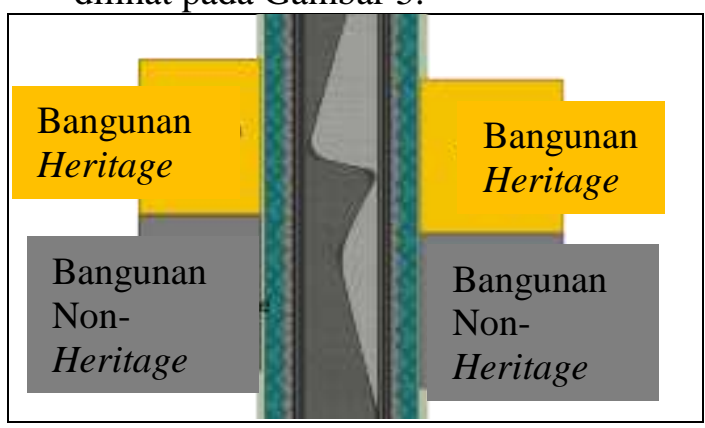

Gambar 5. Pola Jalan

\subsubsection{Street Furniture}

Untuk mendukung pengguna pedestrian di Kawasan Braga, pedestrian dilengkapi dengan street furniture seperti pada Gambar 6 agar memberikan kenyamanan lebih kepada pengguna kawasan.

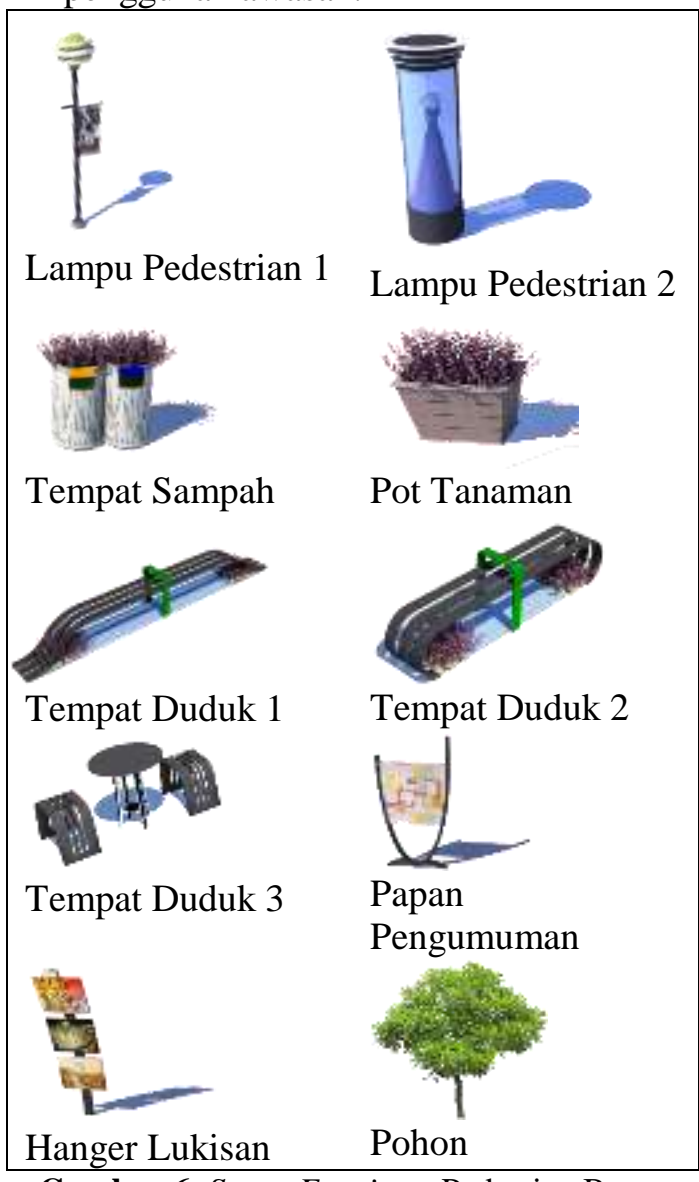

Gambar 6. Street Furniture Pedestian Braga

Pola perletakan street furniture dapat dilihat pada Gambar 7.

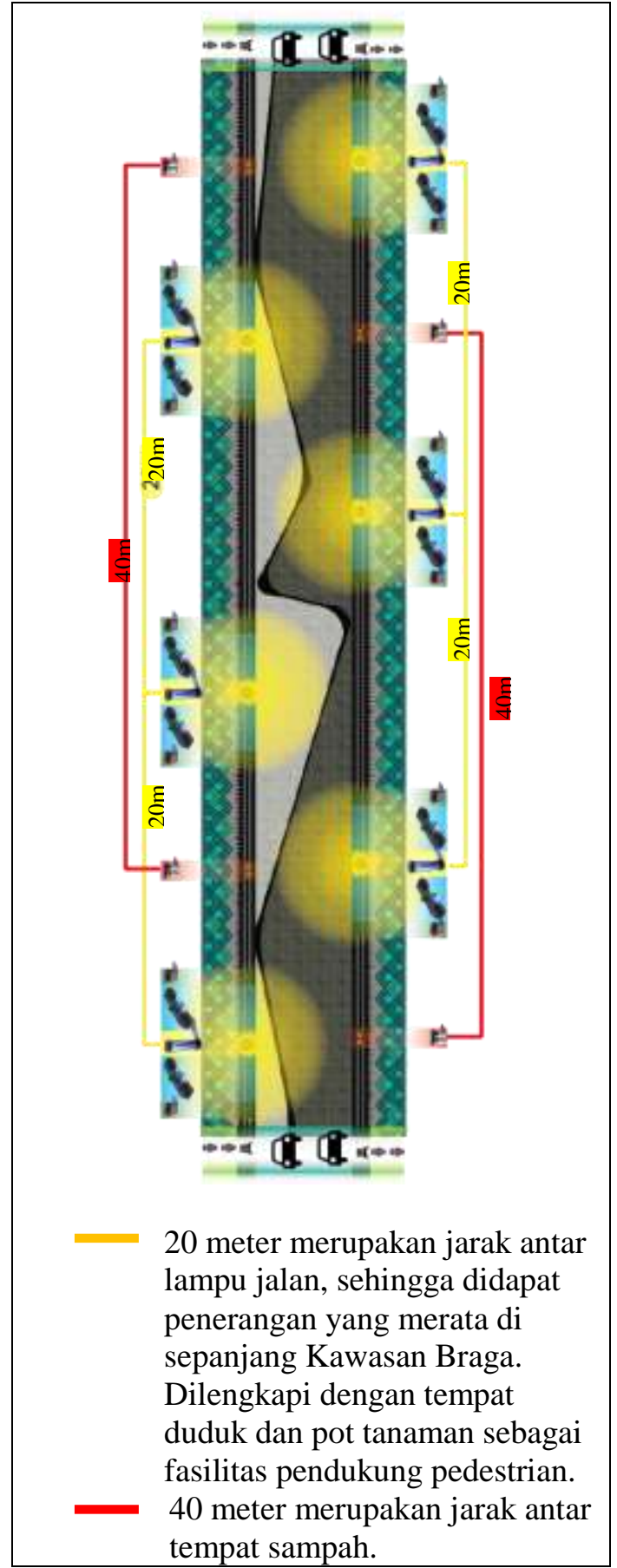

Gambar 7. Pola Perletakan Street furniture

\subsubsection{Titik Simpul}

Titik simpul atau nodes merupakan titik-titik pertemuan kendaraan bermotor dan pejalan kaki. Dianalisis dan diaplikasikan untuk kebutuhan revitalisasi Kawasan Braga seperti Tabel 3. 
Tabel 3. Nodes Kawasan Braga

\begin{tabular}{|c|c|}
\hline Nodes 2 & \\
\hline$y=4$ & $\begin{array}{l}\text { - Halte bus, angkot dan } \\
\text { taksi } \\
\text { - Area manuver } \\
\text { kendaraan } \\
\text { - Ruang transisi dari } \\
\text { titik temu pejalan kaki } \\
\text { - Parkir Sepeda } \\
\end{array}$ \\
\hline Nodes 3 & \\
\hline & $\begin{array}{l}\text { - Ruang transisi dari } \\
\text { titik temu pejalan kaki } \\
\text { - Area manuver } \\
\text { kendaraan } \\
\text { - Drop out kendaraan }\end{array}$ \\
\hline Nodes 4 & \\
\hline & $\begin{array}{l}\text { - Ruang transisi dari } \\
\text { titik temu pejalan kaki } \\
\text { - Area manuver } \\
\text { kendaraan } \\
\text { - Drop out kendaraan }\end{array}$ \\
\hline Nodes 5 & \\
\hline & $\begin{array}{l}\text { - Ruang transisi dari } \\
\text { titik temu pejalan kaki } \\
\text { - Area manuver } \\
\text { kendaraan } \\
\text { - Drop out kendaraan }\end{array}$ \\
\hline Nodes 6 & \\
\hline & $\begin{array}{l}\text { - Halte bis, angkot dan } \\
\text { taksi } \\
\text { - Area manuver } \\
\text { kendaraan } \\
\text { - Ruang transisi dari } \\
\text { titik temu pejalan kaki } \\
\text { - Parkir Sepeda } \\
\end{array}$ \\
\hline
\end{tabular}

\subsubsection{Fasilitas Parkir}

Berdasarkan kebutuhan ruang dan analisis Kawasan Braga, terdapat 3 lokasi parkir. Lokasi tersebut berada di sub-sub ditrick sehingga tidak mengganggu area utama kawasan, seperti pada Gambar 8.

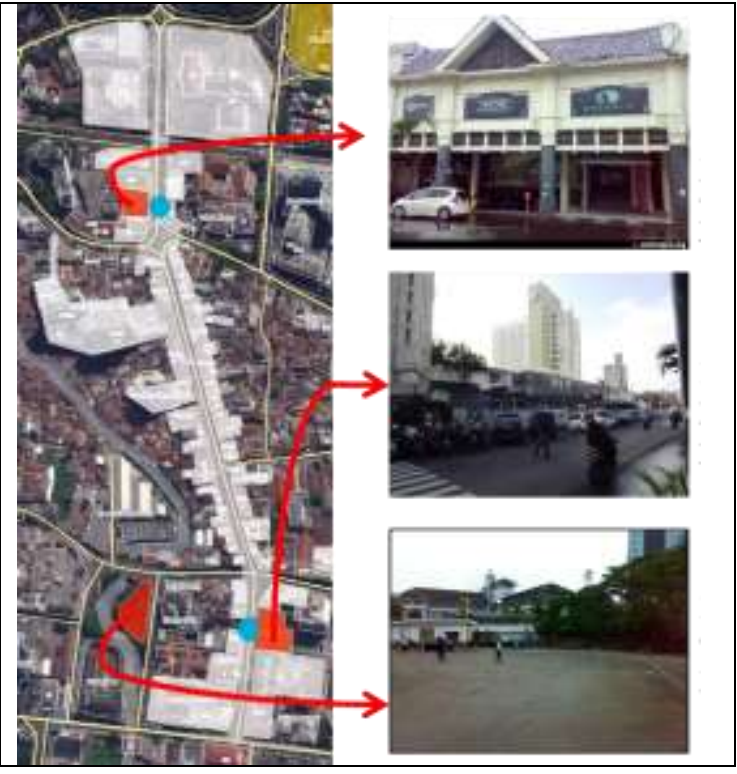

Gambar 8. Fasilitas Parkir

\subsubsection{Mall Bawah Tanah}

Pengembangan kawasan untuk meningkatkan kembali perekonomian Kawasan Braga. Perlu menambah retail atau pengembangan usaha retail yang sudah ada. Menambah area komunal untuk kegiatan ekonomi kreatif, maka perlu lahan untuk mewadahi kegiatan tersebut.

Pengembangan kegiatan perokonomian adalah menjadikan ruang bawah tanah sebagai area pedestrian, komunal dan pertokoan yang baru.

$$
\text { Pada Gambar } 9
$$

diilustrasikan potongan mall bawah tanah dengan pedestrian yang ada di atasnya.

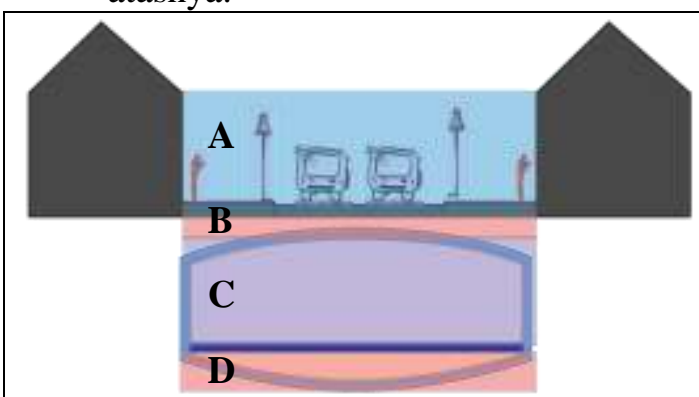
A. Pedestrian
B. Sanitasi
C. Mall bawah tanah
D. Sanitasi

Gambar 9. Potongan Pedestrian Dengan Mall Bawah Tanah 


\subsubsection{Zonasi Mall Bawah Tanah}

Zonasi Mall bawah dibuat bedasarkan oleh pembagian zonasi berdasarkan layer atau zonasi kawasan pedestrian, seperti pada Gambar 10.

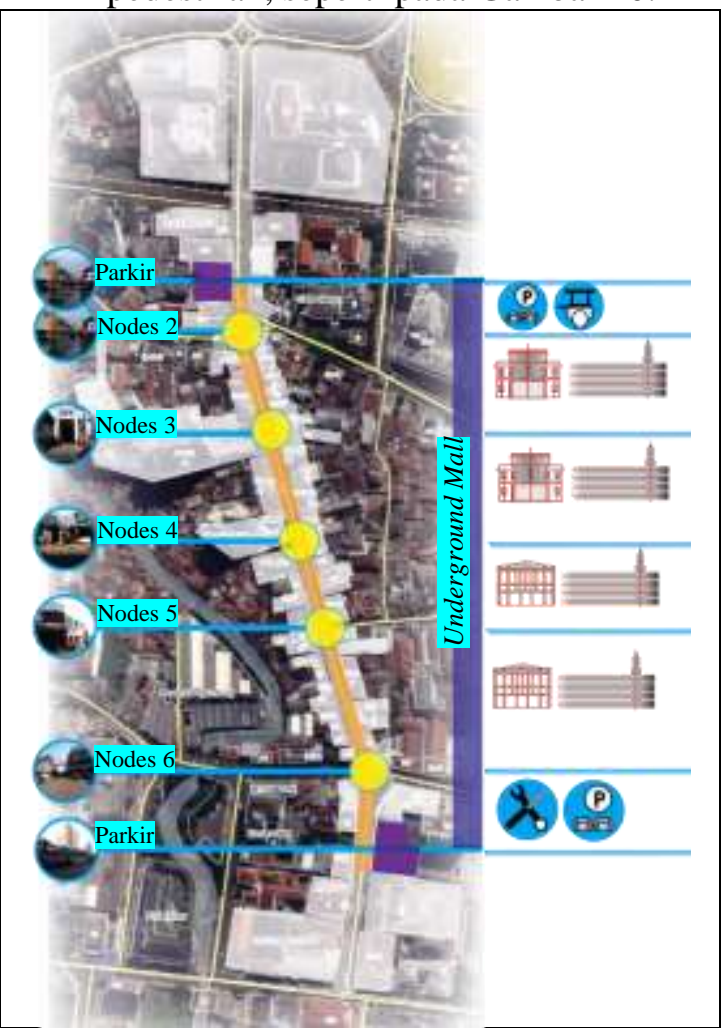

Gambar 10. Respon Zonasi Mall Bawah Tanah

\subsubsection{Fasade Mall Bawah Tanah}

Tampilan fasade retail mall bawah tanah dan fasilitas lainnya mengacu pada bentuk-bentuk dari langgam art deco seperti bulat, kotak, oval, segitiga atau bentuk geometris lainnya.

Berdasarkan hasil analisis pada bangunan-bangunan langgam art deco yang ada di Kawasan Braga, maka di dapatkan pola bangunan seperti pada Gambar 11.

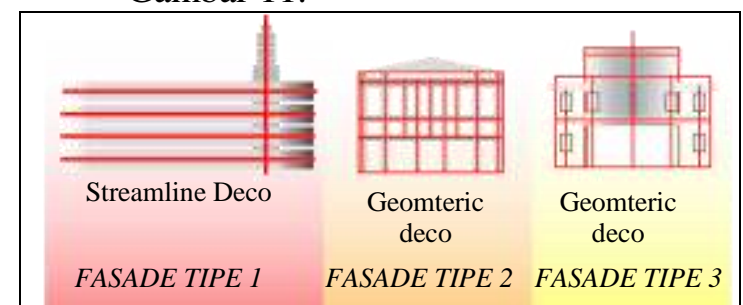

Gambar 11. Analisis Tampilan Fasade
Dengan memadukan ketiga pola langgam art deco berdasarkan hasil analisis bangunan-bangunan art deco di Braga, akan membuat retail mall bawah tanah bervariasi, tidak monoton dengan bentuk kotak-kotak yang monoton.

\subsubsection{Struktur Mall Bawah Tanah}

Penggalian terowongan mall bawah tanah mengunakan metode centre drift.

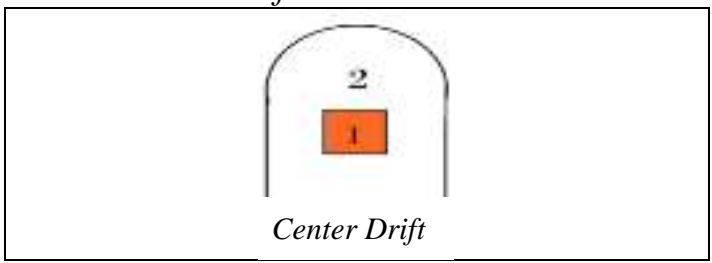

Gambar 12. Metode Centre Drift

(Sumber: Aphiin. 2012)

Metode centre drift adalah suatu metode yang menggali terlebih dahulu sebuah lubang bukaan berukuran kecil sepanjang lintasan terowongan yang kemudian diperbesar sampai membentuk penampang yang direncanakan, seperti pada Gambar 12.

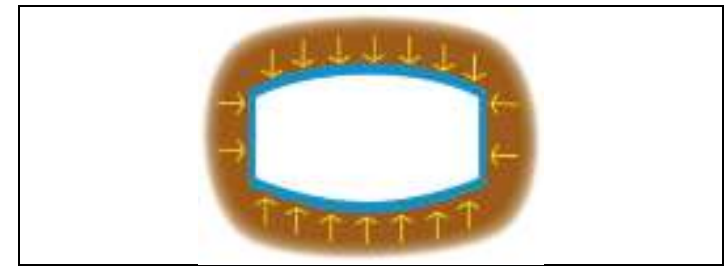

Gambar 13. Metode Perkuatan Dinding Terowongan

Pada Gambar 13 diilustarikan perkuatan dinding terowongan dengan menerapkan sistem struktur cangkang, sehingga penyebaran gaya tekan dapat disalurakan secara merata.

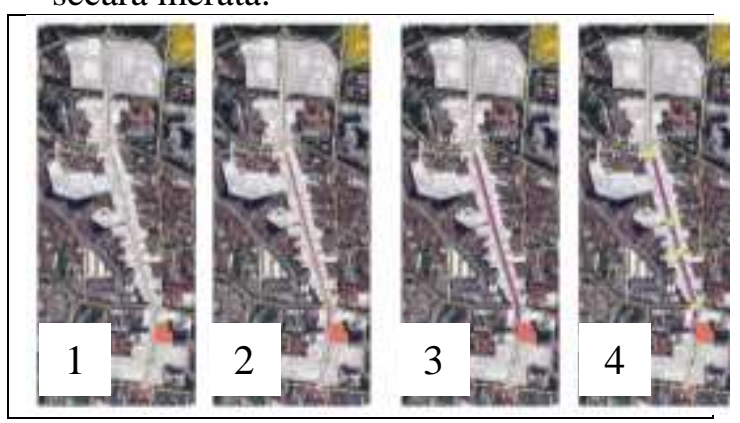

Gambar 14. Tahapan Penggalian Terowongan 
Pada Gambar 14 diilustarikan tahapan penggalian terowongan yang akan dilakukan dengan 4 tahap, yaitu:

Tahap 1 : Menggali lahan untuk parkir basement di bangunan Sarinah

Tahap 2 : Menentukan "center" dari lubang yang direncanakan dan digali horisontal dari bangunan Sarinah hingga nodes 2.

Tahap 3 : Setelah membuat "center" terowongan, selanjutnya memperluas terowongan hingga mencapai luas terowongan yang diinginkan.

Tahap 4 : Membuat perlubangan ke atas pedestrian untuk digunakan sebagai sirkulasi vertikal mall dan pedestrian.

\subsubsection{Konservasi Bangunan Heritage}

Tampilan kawasan bangunan akan dikonservasi berdasarkan peraturan-peraturan yang berlaku untuk bangunan heritage di Kawasan Braga. Tampilan kawasan akan dikonservasi dengan mempertahankan langgam Arsitektur Art deco dengan metode fixing, painting dan re-use, seperti digambarkan pada Gambar 15.

1. Fixing

Bangunan-bangunan yang mengalami kerusakan fisik fasade diperbaiki untuk mengembalikan bentuk fasade asli bangunan.

\section{Painting}

Bangunan di cat dengan warna utama putih krem, pada bagian detail-detail bangunan seperti list dan ornament bangunan. Ornamen bangunan dicat dengan warnawarna art deco dan disesuaikan dengan fasade bangunan agar bangunan terlihat lebih menarik.

3. Re-use

Bangunan-bangunan yang tidak terpakai dimanfaatkan kembali sebagai ruang ekonomi kreatif, seperti factory outlet dan boutiq store.

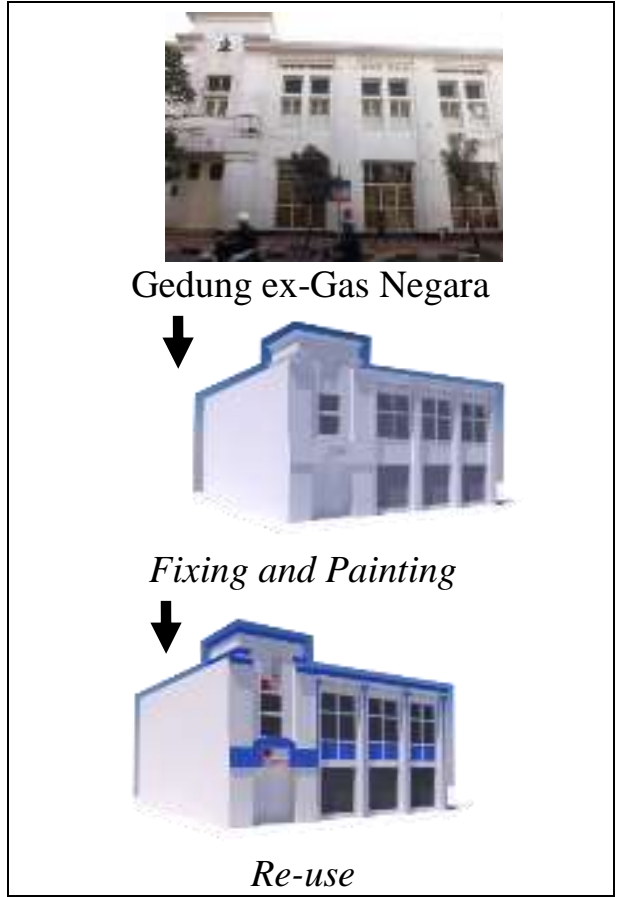

Gambar 15. Redesain Bangunan Konservasi

\subsubsection{Kegiatan Ekonomi Kreatif}

Pada Gambar 16 merupakan hasil analisis perkembangan kegiatan ekonomi kreatif di Kota Bandung. Bidang fesyen yang mendominasi perkembangan ekonomi kreatif di Kota Bandung akan dikembangkan di Kawasan Braga, sebagai usaha pengembangan perekonomian Kawasan Braga, Bidang fesyen juga mencerminkan sejarah Kawasan Braga sebagai kawasan lifestyle bagi orangorang Eropa di Indonesia.

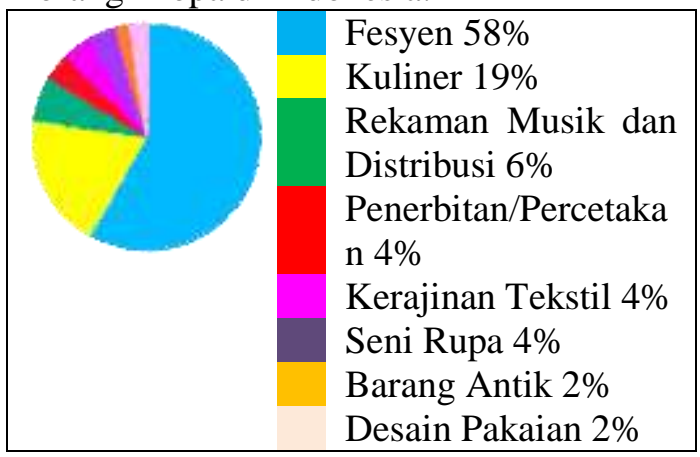

Gambar 16. Hasil Survey Ekonomi Kreatif di Bandung Tahun 2011

(Sumber: Iskandar, 2011)

Berikut adalah respon desain kegiatan ekonomi kreatif fesyen di Kawasan Braga.

1. Pengembangan Usaha Kretatif 
Pengembangan usaha kreatif dapat didorong melalui kegiatan komunitas-komunitas di bidang ekonomi kreatif khususnya bidang fesyen, seperti seminar dan workshop

2. Promosi

Promosi merupakan media pengembangan usaha fesyen ke publik Kota Bandung maupun di Indonesia, sehingga karya-karya desainer dari Braga dapat dikonsumsi masyarakat Indonesia bahkan dunia.

3. Investasi

Dengan Braga mengusung tema fesyen pada kawasannya, diharap kan menjadi daya tarik investor dalam bidang fesyen. Seperti, menambah jumlah retail, acara fesyen dan penguatan tampilan kawasan.

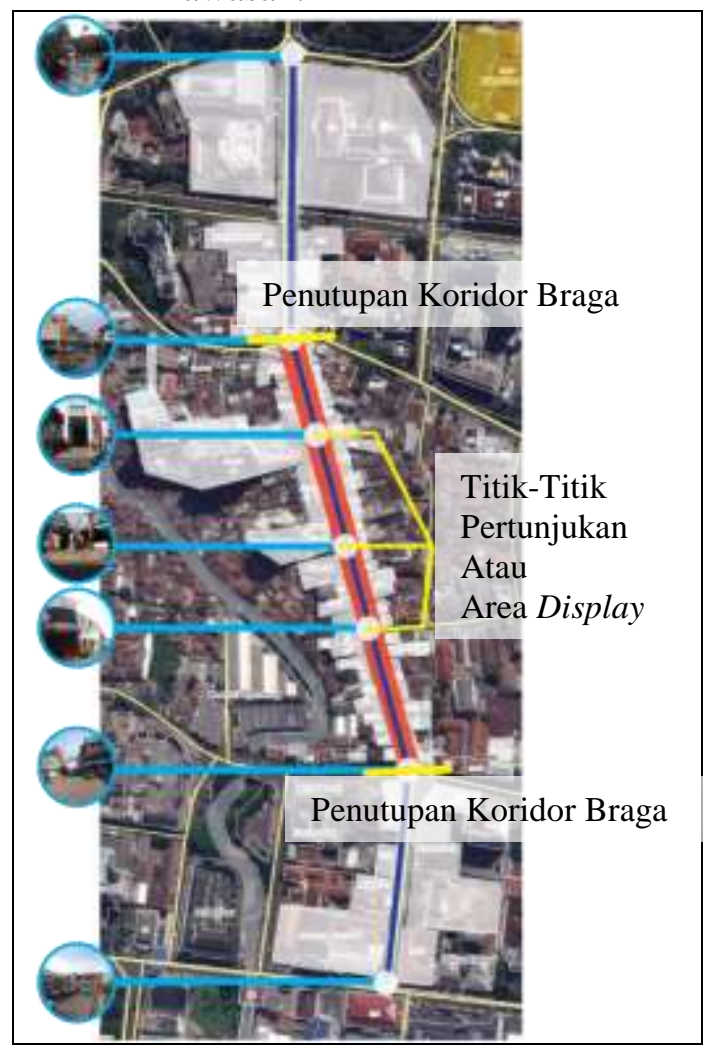

Gambar 17. Simulasi Penutupan Jalan Dan Titik Pertunjukan Saat Acara Berlangsung

Gambar 17 merupakan ilustari dari penutupan Jalan Braga selama berlangsungnya acara yang merupakan dari kegiatan promosi Kawasan Braga.

\section{KESIMPULAN (KONSEP DESAIN)}

Kawasan Braga berada dipusat Kota Bandung, dengan panjang jalan lebih kurang 700 meter. Kawasan Braga menjadi penghubung antar kawasan, seperti Kawasan Bandung Utara dengan Kawasan Alun-Alun Bandung.

Konsep revitalisasi Kawasan Braga direncanakan agar tidak hanya tampil menarik namun berdampak positif terhadap kegiatan perekonomian di Kawasan Braga.Konsep revitalisasi Kawasan Braga juga mengacu pada sejarah perkembangan Braga dan Braga pada saat ini.

Mengembalikan citra pedestrian yang manusiawi, trotoar yang tidak sebatas untuk jalan setapak tetapi juga merupakan bagian ruang terbuka yang mempunyai fungsi rekreatif, bisnis, ekonomi dan berkomunitas. Dapat dilihat pada Gambar 18 yang merupakan desain dari fungsi pedestrian yang dapat digunakan berbagai macam kegiatan.

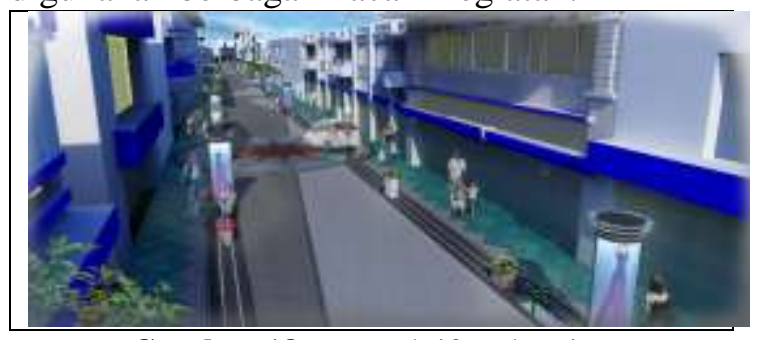

Gambar 18. Perspektif Pedestrian

Pada Gambar 19 merupakan desain mall bawah tanah sebagai pengembangan kawasan yang bertujuan untuk meningkatkan perekonomian dan area berkomunitas di Kawasan Braga yang dapat di isi oleh pelaku ekonomi kreatif khususnya dibidang fesyen.

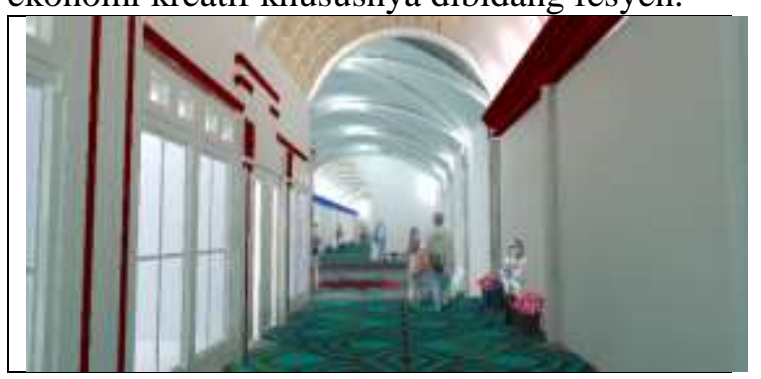

Gambar 19. Perspektif Mall Bawah Tanah

Pada Gambar 20 merupakan pintu masuk mall bawah tanah yang berada pada nodes 2 


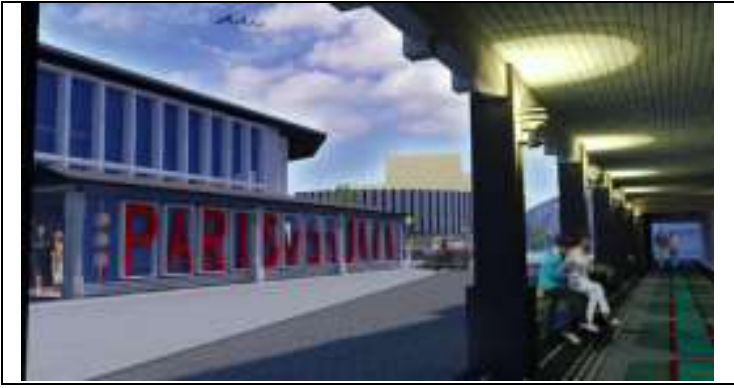

Gambar 20. Perspektif Nodes 2

Upaya konservasi bangunan-bangunan tua di Braga agar tampil lebih menarik, sehingga menjadi aset pusaka Kota Bandung. Pada Gambar 21 merupakan contoh upaya konservasi bangunan-bangunan heritage di Kawasan Braga ditambah dengan fasilitas ruang terbuka sebagai upaya pengembangan area berkomunitas.

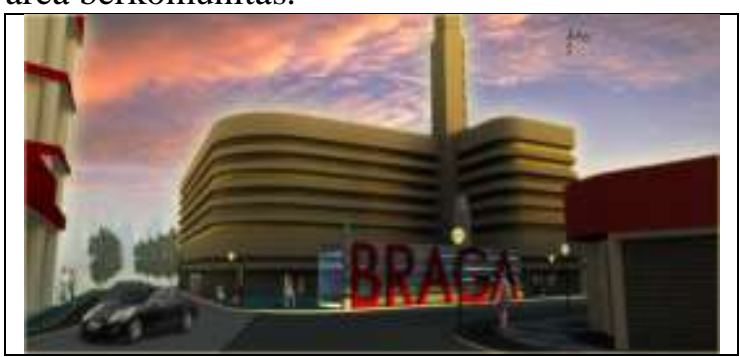

Gambar 21. Perspektif Nodes 6

Menumbuhkan kegiatan ekonomi baru di Braga dengan memanfaatkan perkembangan ekonomi kreatif di Kota Bandung. Bidang fesyen dipilih karena sesuai dengan sejarah Kawasan Braga yang terkenal dengan kawasan mode di Indoesia dan sesuai dengan perkembangan ekonomi kreatif yang tumbuh dengan pesat di Kota Bandung.

Revitalisasi Kawasan Braga bertujuan untuk mendorong terjadinya kegiatan ekonomi jangka panjang, baik dari segi produsen seperti ekonomi kreatif dan segi konsumen seperti kegiatan kepariwisataan di Kota Bandung.

Braga sebagai kawasan pusaka Kota Bandung dapat dijadikan obyek percontohan untuk pengembangan kota pusaka diberbagai kawasan heritage di Kota Bandung, sehingga keberlangsungan kegiatan Braga dapat dijaga secara berkelanjutan dan menjadi ruang dalam kota yang aman, nyaman dan produktif.

\section{REFERENSI}

Iskandar, Gustaff H., 2011, Resume Angket Survey Pekembangan Ekonomi Kreatif Kota Bandung, Bandung

Panero, Julius dan Zelnik, Martin, 1980. Human Dimension \& Interior Space. London: The Architectural Press.

Mulyati, Ahda dan Fitria Junaeny, 2009. Pusat Pertokoan dengan Konsep Pedestrian Mall di Kota Palu. Jurnal "ruang" Volume 1 Nomor 1. Fakultas Teknik Jurusan Arsitektur Universitas Tadulako.

Dep. Pekerjaan Umum, 2011, Pedoman Revitalisasi Kawasan, Peraturan Menteri Pekerjaan Umum Nomor 18/PRT/M/2011, Jakarta.

Aphiin. 2012. Metode Penggalian

Terowongan,

https://fileq.wordpress.com/category/ilmupertambangan/teknik-terowongan/, (diakses 25 Oktober 2015)

Administrator. Kota Pusaka Indonesia, http://kotapusaka.com/index.php?option=co $\underline{\mathrm{m}}$ _content $\&$ view $=$ article $\& \mathrm{id}=23 \&$ Itemid $=1$ 1 , (diakses 5 Desember 2014) 